\title{
Congenital Cytomegaloviral Infection Causing Severe Pulmonary Hypertension in a Newborn with a HIV Seropositive Mother - A Case Report from Eastern India
}

\author{
Aroni Chatterjee ${ }^{1}$, Sabbir Ansari ${ }^{1}$, Agniswar Sarkar', Lopamudra Mishra ${ }^{2}$, Mala Bhattacharya ${ }^{2}$, Sanath Kumar Ghosh ${ }^{2}$ and Nilanjan \\ Chakraborty ${ }^{1 *}$ \\ ${ }^{1}$ ICMR Virus Unit, ID \& BG Hospital campus, Kolkata, West Bengal, India \\ ${ }^{2}$ B.C. Roy Post Graduate Institute of Pediatric Sciences, Kolkata, West Bengal, India
}

\begin{abstract}
Mother-to-child transmission is considered to be the main cause of HIV infection in children below 10 years of age. Several opportunist pathogens take the advantage of this compromised immune condition and manifest their deadly effects. Cytomegalovirus (HCMV) is one of the most dreaded opportunist pathogen associated with HIV infection and perhaps the leading cause of congenital infection in the world. In this study we report a very interesting case where a HIV seropositive woman delivers a HIV seronegative child who suffered from pulmonary hypertension and pulmonary interstitial emphysema from the time of birth due to congenital cytomegaloviral infection. This case report suggests that suitable prophylactic measures should be taken by pregnant women especially when they are in an immunocompromised condition to evade being targeted by HCMV and prevent its vertical transmission. Early diagnosis, intravenous gancyclovir administration along with ionotropic support, mechanical ventilation and other respiratory supports is irreplaceable for treating this condition.
\end{abstract}

Keywords: HIV; Human cytomegalovirus; Congenital; Pulmonary hypertension; Emphysema

\section{Introduction}

HIV infection among women has increased globally by considerable proportions, but significant achievements have been made in developed countries to prevent mother to child transmission. Mother-to-child transmission or vertical transmission is generally considered to be the main cause of HIV infection in children below 10 years of age. HIV can be easily transmitted during pregnancy, delivery or during breastfeeding. Among the infected newborns who are not breastfed, about $75 \%$ are believed to have contracted the virus around the time of labor or delivery [1]. The epidemiology of HIV among infants mainly results from the rapidly rising incidence of HIV among women of childbearing age and the significant effect of Anti Retroviral Therapy (ART) on mother-to-child transmission. Globally women constitute approximately $47 \%-50 \%$ of HIV-positive adults [2]. Though combined ART has reduced the risk of HIV vertical transmission from mother to child but the risk of transmitting a viral opportunist infection to an infant congenitally from a HIV infected mother is still a major point of concern. Human Cytomegalovirus (HCMV) is one of the most dreaded opportunist pathogen associated with HIV infection and perhaps the leading cause of congenital infection in the world, affecting roughly 7 to $10 \%$ of all pregnancies. Congenital HCMV infection has recently emerged as one of the most critical public health problems in India with $80-90 \%$ of the adult women showing prevalence of CMV IgG antibodies in their blood [3,4]. In case of HCMV conveyance from mother to child, the danger of intrauterine transmission is highest when primary infection happens amid pregnancy. $10 \%-12 \%$ of the infected newborns have symptomatic diseases involving multiple organs and a significant percentage of them develop serious health issues including severe lung involvement, microcephaly, chorioretinis, neurologic deficits, pneumonitis etc. [5]. Congenital HCMV infection may occur in infants of mother who are seropositive for CMV prior to pregnancy. In India the occurrence and epidemiology associated with this subject has remained largely unexplored [6]. In this study we report a very interesting case where a HIV seropositive woman delivers a HIV seronegative child who suffered from pulmonary hypertension and pulmonary interstitial emphysema from the time of birth due to congenital cytomegaloviral infection. The child was admitted to the neonatal care unit of a major pediatric hospital in West Bengal, India.

\section{Case Report}

A 22 year old HIV seropositive woman (undergoing ART) in her first normal pregnancy delivered vaginally a 2560 gram male child. Abnormal physical weakness (Asthenia) and flu like symptoms in the mother complicated the pregnancy course at 29-week gestation. HIV viral load in blood was found to be greatly reduced at this stage. USG performed during this phase didn't show any anomalous findings. Immediately after birth the infant suffered from troubled breathing and acute respiratory distress. Conventional mechanical ventilation along with inotropic (dobutamine) support, NO inhalation and oxygen support was initiated from the $3^{\text {rd }}$ day of birth. Chest X-Ray confirmed alveolointerstitial pneumonitis and severe pulmonary interstitial emphysema. Antibiotic therapy including amoxicillin, amikacin and cefotaxime was initiated immediately but didn't show any promising improvement. HIV fourth generation test and HIV viral load (tested 12 hours after birth from blood) both gave negative results for the infant. CD4 count was found to be $>1500$ and CD4\% was over $25 \%$. Cultures for bacteria and fungi were found to be negative. TORCH screening performed with the child's blood gave HCMV positive but Rubella and Toxoplasma

${ }^{*}$ Corresponding author: Dr. Nilanjan Chakraborty, ICMR Virus Unit, ID \& BG Hospital, GB4, 57 Dr. SC Banerjee Road, Beliaghata, Kolkata - 700010, India, Tel: +91-9163785518; Fax: +9133-23537424; E-mail: nilanjan_19@yahoo.com

Received March 29, 2016; Accepted April 20, 2016; Published April 27, 2016

Citation: Chatterjee A, Ansari S, Sarkar A, Mishra L, Bhattacharya M, et al. (2016) Congenital Cytomegaloviral Infection Causing Severe Pulmonary Hypertension in a Newborn with a HIV Seropositive Mother - A Case Report from Eastern India. J AIDS Clin Res 7: 567. doi:10.4172/2155-6113.1000567

Copyright: (c) 2016 Chatterjee A, et al. This is an open-access article distributed under the terms of the Creative Commons Attribution License, which permits unrestricted use, distribution, and reproduction in any medium, provided the original author and source are credited. 
Citation: Chatterjee A, Ansari S, Sarkar A, Mishra L, Bhattacharya M, et al. (2016) Congenital Cytomegaloviral Infection Causing Severe Pulmonary Hypertension in a Newborn with a HIV Seropositive Mother - A Case Report from Eastern India. J AIDS Clin Res 7: 567. doi:10.4172/21556113.1000567

Page 2 of 3

negative results. ELISA test for CMV IgM and IgG with blood serum from the mother and baby both gave positive results. PCR amplification test for CMV DNA detection in blood serum of the baby were found to be positive. High HCMV viral load was found in the infant's blood $\left(9.80 \times 10^{6}\right.$ DNA copies $\left./ \mathrm{ml}\right)$. Echocardiography confirmed a normal heart but observed pulmonary hypertension with hypertrophy of right ventricle. Despite giving immediate mechanical ventilation to the new born child, acute refractory hypoxemia developed within few hours of birth Biological abnormalities were noted including thrombocytopenia $\left(37 \times 10^{9} / \mathrm{L}\right)$, neutropenia $\left(0.87 \times 10^{9} / \mathrm{L}\right)$, elevated CRP level $(89 \mathrm{mg} / \mathrm{L})$, and elevated conjugated bilirubinemia (total serum bilirubin $6.8 \mathrm{mg} /$ $\mathrm{dL}$; direct bilirubin $4.5 \mathrm{mg} / \mathrm{dL}$ ). Liver function was greatly hampered with elevated AST/ SGOT (189 IU/L) and ALT /SGPT (197 IU/L) levels but the kidney functions were found to be normal. In spite of the HIV negative status of the child Zidovudine $(2 \mathrm{mg} / \mathrm{kg} / \mathrm{d})$ was administered to the infant as a prophylactic measure but was discontinued after 5 days following acute HCMV detection. Despite ventilation the infant's condition deteriorated. Intravenous gancyclovir treatment $(8 \mathrm{mg} / \mathrm{kg} / \mathrm{d})$ was initiated 5 days postnatal and continued for approximately 5 weeks along with systematic conventional mechanical ventilation. Significant improvement was visible after about 24 days treatment and thereafter respiratory distress gradually decreased. After 5 weeks the child was removed from ventilation but oxygen support was carried on for another 15 days. Thereafter chest $\mathrm{x}$-ray performed showed diminished lung involvement. Blood test for HCMV DNA by PCR confirmed rapid subsidence of HCMV infection. HIV diagnostic tests and HIV viral load detection tests with the infant's blood were again performed at 14 days, 28 days and 48 days postnatal. The tests yielded negative results and CD $4 \%$ was found to be still over $25 \%$. Opthalmologic and neurological status was found to be normal. Intrahepatic cholestasis gradually resolved. The child was kept on a 1 week observation. But suddenly on the $2^{\text {nd }}$ day of observation, the child presented severe respiratory distress and showed severe hypoxemia with derogatory hypercapnia. An atrial septostomy was planned to be performed but the child expired next day following respiratory blockage and heart failure. Post mortem examination and lung biopsy confirmed the cause to be acute HCMV infection with adequate lung involvement (Figure 1).

\section{Discussion}

We report a case of a HIV seronegative infant born to a HIV seropositive mother, affected with congenital cytomegaloviral infection occurring at birth. HCMV which is a typical opportunist viral pathogen associated with HIV infection caused severe pulmonary hypertension and refractory emphysema in the infant. Persistent pulmonary hypertension is a known symptom associated with congenital HCMV infection and has been reported in a few cases across the globe [7]. Persistent pulmonary hypertension in newborns can also be caused due to various other factors which include hypoplastic pulmonary vasculature, congenital diaphragmatic hernia, pulmonary hypoplasia, abnormally constricted pulmonary vasculature, meconium aspiration syndrome, idiopathic persistent pulmonary hypertension etc [8-11]. HCMV generally spreads into the pneumonal passage following fetal viremia. Common pathological observations in innately infected fetal lungs following HCMV aggravation are immature and dyselectatic morphology associated with interstitial oedema, gradual invasion and purulent aggravation [12]. Vasculitis is suspected to be another pathogenic
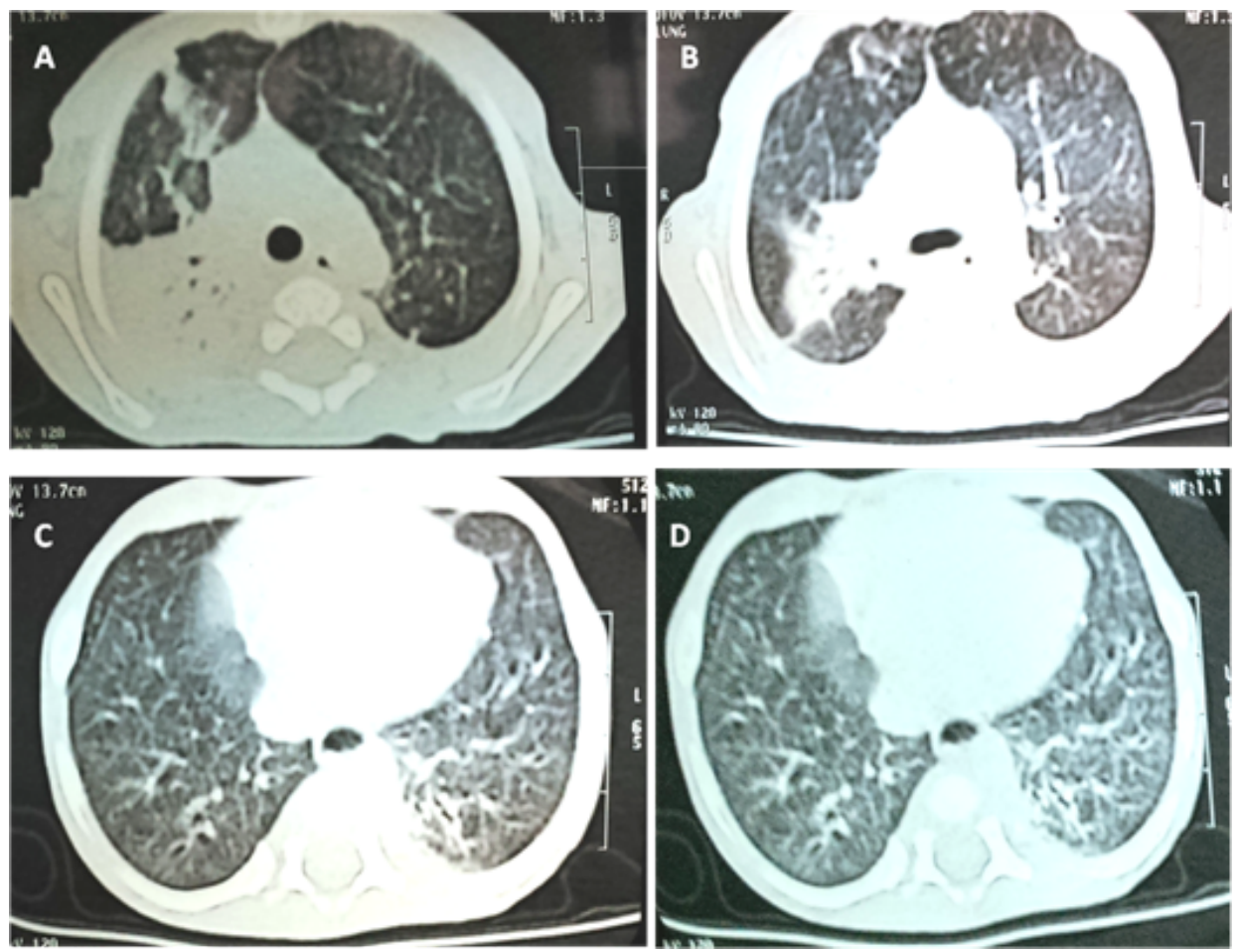

A- Consolidation of right upper lobe (posterior segment and part of anterior segment). Dyselectatic band is also seen in right lobe.

B- Peribronchial thickening is seen in left lobe. Ground glass opacity is present in both lung fields more on left side, suggestive of alveolitis. Atelectatic band is also seen in lingual lobe of left lung.

C- Bilateral increased pulmonary vascularity. Non-specific diffused interstitial emphysema visible.

D- Left lung lower lobe posterior basal segment shows pneumonitis with reticulonodular pattern.

Figure 1: Post mortem examination and lung biopsy. 
Citation: Chatterjee A, Ansari S, Sarkar A, Mishra L, Bhattacharya M, et al. (2016) Congenital Cytomegaloviral Infection Causing Severe Pulmonary Hypertension in a Newborn with a HIV Seropositive Mother - A Case Report from Eastern India. J AIDS Clin Res 7: 567. doi:10.4172/21556113.1000567

Page 3 of 3

mechanism prompting neonatal death [13]. Pneumonic hypertension and alveolar-interstitial pneumonitis which are regular complexities connected with congenital HCMV infection was also observed in this case. HIV serpositive women undergoing active Anti Retroviral Therapy for a considerable time span are at a much reduced risk to transmit the virus to their children at the time of pregnancy [14]. These women though are very much susceptible to be infected with opportunist viral pathogens like HCMV which gets vertically transmitted to the child. No report from India has yet been documented discussing the aggravation of congenital HCMV infection with the background of an HIV infected mother as the cause of pulmonary hypertension and emphysema in neonates. Actually in India studies regarding prevalence of birth defects due to congenital cytomegaloviral infections are indeed very limited. The true frequency of recurrent HCMV vertical transmissions from HIV infected mothers remains hard to determine due to lack of efficient documentations. Primary infection in mothers continues to be the major cause of infection in infants with significant rate of morbidity. Respiratory support including conventional mechanical ventilation should be initiated and kept up as long as pneumonic hypertension perseveres, along with an immediate and detailed regime of anti-HCMV drug [15]. These measures may help to control the respiratory status as long as the antiviral treatment remains viable. Currently, among the four licensed anti-HCMV drugs gancyclovir, valgancyclovir, foscarnet and cidofovir, gancyclovir finds maximum usage in India. With the rapid advent of these antiviral therapies, significant advances have been achieved in the treatment and prevention of HCMV infection [16]. This has resulted in a dramatic breakthrough in the field of medical intervention though the benefits of early treatment with gancyclovir, the right dosage and duration remain controversial while treating patients with immunocompromised background $[17,18]$. Congenitally infected newborn children with end organ diseases for example, pneumonitis, oesophagitis, persistent serious thrombocytopenia, and acute sightthreatening chorioretinitis seemed to profit by gancyclovir treatment $[19,20]$. In this case report we have found that when intravenous gancyclovir therapy was associated with prominent respiratory support following an early diagnosis, respiratory status improved and the child recouped. We did not observe any genotoxic side effects. Though the clinical conditions of the infant improved initially but due to the severe lung infiltration by the virus and consecutive damage of the alveolus, the child expired. This case report is perhaps the first documented evidence from India of such an instance where the newborn remain unaffected with the HIV status of the mother but rendered highly susceptible to the vicious attack of congenital HCMV infection manifesting as severe pulmonary hypertension.

\section{Conclusion}

Thus to conclude in the end it is to be pointed out that, this report correctly emphasizes and implicates the severity of HCMV infection causing persistent pulmonary hypertension and derogatory hypercapnia in neonates, of which very few reports have till date been documented worldwide. What makes this case more interesting is the fact that the infant is born to a HIV serpositive mother undergoing ART. The ART treatment greatly reduced the viral load in the mother and the risk of HIV transmission to the child during pregnancy. Thus this report is a perfect document for the medical practitioners in India to understand the gravity of this clinical situation and take timely measures to fight it. Furthermore we suggest that intravenous gancyclovir administration along with mechanical ventilation and other respiratory support is irreplaceable for treating this condition. However, more efficient studies on a larger cohort should be designed and performed to appropriately investigate the clinical benefits of this treatment.

\section{Funding}

The work has been performed with the intramural fund provided by Indian Council of Medical Research, Government of India.

\section{References}

1. Krist AH, Crawford-Faucher A (2002) Management of newborns exposed to maternal HIV infection. Am Fam Physician 65: 2049-2056.

2. Davis SF, Byers RH Jr, Lindegren ML, Caldwell MB, Karon JM, et al. (1995) Prevalence and incidence of vertically acquired HIV infection in the United States. JAMA 274: 952-955.

3. Chakravarty A, Kashyap B, Rathi K (2005) The seroepidemiological study on cytomegalovirus in women of child-bearing age with special reference to pregnancy and maternal-fetal transmission. Indian J Pathol Microbiol 48: 518521

4. Gandhoke I, Aggarwal R, Lal S, Khare S (2006) Congenital CMV infection in symptomatic infants in Delhi and surrounding areas. Indian J Pediatr 73: 10951097.

5. Boppana SB, Pass RF, Britt WJ, Stagno S, Alford CA (1992) Symptomatic congenital cytomegalovirus infection: neonatal morbidity and mortality. Pediatr Infect Dis J 11: 93-99.

6. $\mathrm{Ng} \mathrm{PC}$, Fok TF, Lee $\mathrm{CH}$, Cheung KL, So KW, et al. (1998) Congenital cytomegalovirus infection presenting as severe persistent pulmonary hypertension of the newborn. J Perinatol 18: 234-237.

7. Nicolet EW, Leblanc M, Ville ML, Hubert P, Mitanchez D (2011) Congenital cytomegaloviral infection manifesting as neonatal persistent pulmonary hypertension: report of two cases. Pulm med 293285.

8. Steinhorn RH (2010) Neonatal pulmonary hypertension. Pediatr Crit Care Med 11: S79-84.

9. Rosenzweig EB, Widlitz AC, Barst RJ (2004) Pulmonary arterial hypertension in children. Pediatr Pulmonol 38: 2-22.

10. Greenough A, Khetriwal B (2005) Pulmonary hypertension in the newborn Paediatr Respir Rev 6: 111-116.

11. Murphy JD, Rabinovitch M, Goldstein JD, Reid LM (1981) The structural basis of persistent pulmonary hypertension of the newborn infant. J Pediatr 98: 962967.

12. Grundy JE, Shanley JD, Griffiths PD (1987) Is cytomegalovirus interstitial pneumonitis in transplant recipients an immunopathological condition?. Lancet 2: 996-999.

13. Emery VC (2001) Investigation of CMV disease in immunocompromised patients. J Clin Pathol 54: 84-88.

14. Revello MG, Gerna G (2002) Diagnosis and management of human cytomegalovirus infection in the mother, fetus, and newborn infant. Clin Microbiol Rev 15: 680-715.

15. Demmler GJ (2003) Congenital cytomegalovirus infection treatment. Pediatr Infect Dis J 22: 1005-1006.

16. Ahmed A (2011) Antiviral treatment of cytomegalovirus infection. Infect Disord Drug Targets 11: 475-503.

17. Adler SP, Nigro G, Pereira L (2007) Recent advances in the prevention and treatment of congenital cytomegalovirus infections. Semin Perinatol 31: 10-18.

18. Piazze J, Nigro G, Mazzocco M, Marchiani E, Brancato V, et al. (1999) The effect of primary cytomegalovirus infection on fetal lung maturity indices. Early Hum Dev 54: 137-144.

19. Bissinger AL, Sinzger C, Kaiserling E, Jahn G (2002) Human cytomegalovirus as a direct pathogen: correlation of multiorgan involvement and cell distribution with clinical and pathological findings in a case of congenital inclusion disease. J Med Virol 67: 200-206

20. Malm G, Engman ML (2007) Congenital cytomegalovirus infections. Semin Fetal Neonatal Med 12: 154-159. 